\title{
Fatal collapse due to autonomic dysreflexia during manual self-evacuation of bowel in a tetraplegic patient living alone: lessons to learn
}

This article was published in the following Dove Press journal:

International Medical Case Reports Journal

2 November 2017

Number of times this article has been viewed

\section{Subramanian Vaidyanathan' Bakul M Soni' \\ Paul Mansour ${ }^{2}$ Tun Oo'}

'Regional Spinal Injuries Centre, ${ }^{2}$ Department of Histopathology, Southport and Formby District General Hospital, Town Lane, Southport, UK
Correspondence: Subramanian Vaidyanathan

Regional Spinal Injuries Centre, Southport and Formby District General Hospital, Town Lane, Southport PR8 6PN, UK Email subramanian.vaidyanathan@nhs.net
Background: To identify areas for improvement, the National Health Service in England mandates the review of case reports of patients who have died, which should be translated into improved care for other patients.

Case report: A 49-year-old Caucasian man sustained C-7 tetraplegia in a motorcycle accident in 1992. In 2009, he developed seizures and collapsed in the lavatory on a number of occasions during manual self-evacuation of his bowel. A 24-hour electrocardiogram recording at that time showed sinus rhythm with a maximum heart rate of 97 and a minimum of 39 beats per minute; there were no significant arrhythmias that could have contributed to his episodes of collapse. In 2015, the patient again collapsed while performing manual evacuation of his bowel; on this occasion, he did not suffer a seizure. He was found unresponsive in the bathroom by his daughter, who contacted the emergency services. He recovered consciousness on arrival at the Accident and Emergency Department. A noncontrast computed tomography scan of his head revealed no acute intracranial pathology. In 2016, he suffered a fatal collapse in the lavatory, again while performing manual bowel evacuation. At autopsy, no other significant disease was found that might have caused death, and given the clinical history, the cause of death was recorded as autonomic dysreflexia.

Conclusion: There were delays in 1) recognizing that his episodes of collapse in the lavatory were due to autonomic dysreflexia induced by manual bowel evacuation; 2) recommending the prior application of topical $2 \%$ lidocaine jelly to prevent or limit autonomic dysreflexia occurring during manual bowel evacuation; and 3) considering alternative bowel management such as stimulant laxatives, transanal irrigation, or colostomy, which could have prevented the occurrence of autonomic dysreflexia caused by manual evacuation.

Keywords: spinal cord injury, autonomic dysreflexia, fatality, topical lidocaine, bowel evacuation, colostomy

\section{Introduction}

The National Health Service (NHS) in England stipulates that much greater priority should be given, across the health and social care system, to learning from potentially avoidable deaths; without this, opportunities to improve care for other patients on future will continue to be missed. The NHS mandates that the case reports of all patients who have died must be screened to identify concerns and possible areas for improvement and the outcome should be documented. Change is needed to make sure that there is learning from the deaths of patients and that this quickly translates into improved care for other patients. ${ }^{1}$

Autonomic dysreflexia, which is often triggered by unpleasant visceral or sensory stimuli below the injury level, is characterized by an episodic, massive sympathetic 
discharge that causes severe hypertension associated with bradycardia, which if severe enough can lead to asystole and pulseless electrical activity.

Spinal cord injury may lead to cardiac arrhythmias. A review of the MEDLINE database by Hector et al revealed the incidence of bradycardia to be $17 \%-77 \%$ for individuals with cervical spinal cord injury and $0.13 \%$ for those with thoracolumbar spinal cord injury. ${ }^{2}$

Studies on cardiovascular abnormalities after spinal cord injury show that mostly all patients with motor complete cervical injuries (American Spinal Injury Association [ASIA] Grades A and B) develop bradycardia, 68\% of them are hypotensive, $35 \%$ of them require vasopressors, and $16 \%$ of them have primary cardiac arrest. Among persons with motor incomplete cervical injuries (ASIA Grades $\mathrm{C}$ and D), 35\%-71\% of them develop bradycardia, but few have hypotension or require vasopressors. Among patients with thoracolumbar injuries, $13 \%-35 \%$ of them develop bradycardia. $^{3-5}$ Thus, more cranial and motor complete injuries seemed to increase the incidence of bradycardia. The primary mechanism underlying these observations appears to involve the acute autonomic imbalance created by the disruption of sympathetic pathways located in the cervical cord. ${ }^{4}$ In a patient with spinal cord injury, reported by Trønnes and Berg, dysreflexia was triggered by a distended urinary bladder; this patient was successfully resuscitated after developing asystole and, after subsequent treatment with intermittent catheterization and implantation of a permanent pacemaker, remained asymptomatic and without registered arrhythmia 12 months later. ${ }^{6}$

Here we report a tetraplegic patient who developed fatal autonomic dysreflexia and collapse during manual selfevacuation of the bowel. This case is a poignant reminder to health professionals and caregivers that precipitating causes for autonomic dysreflexia should be identified and treated promptly to avoid potentially fatal consequences.

\section{Case report}

A 49-year-old Caucasian man sustained C-8/T-1 tetraplegia in a motorcycle accident in 1992, in which he lost the control of his motorcycle while overtaking on a bend and hit a patch of gravel; no other persons were involved. Neurological examination revealed motor power of Grade 5 in all groups of muscles of both right and left shoulders, elbows, and wrists. Handgrip showed Grade 3 plus motor power, whereas thumb muscles showed Grade 5. Following spinal fixation, he underwent rehabilitation and had since been leading an active life.
In 2009 , this patient suffered frequent collapses in the lavatory during manual evacuation of the bowel. He experienced no palpitations, shortness of breath, chest pain, or dizziness correlating with or prior to these episodes of collapses. None of the episodes of collapses was witnessed. A 24-hour electrocardiogram (ECG) recording showed sinus rhythm with a maximum heart rate of 97 and a minimum of 39. There were no significant cardiac arrhythmias that might have contributed to his episodes of collapse. The collapses were therefore labeled as secondary to epilepsy, which itself attributed to a side effect of baclofen that was therefore stopped, after which he apparently suffered no further episodes of collapse. This patient did not have an ECG recording during any of the collapses; electroencephalogram recording was not performed at any time. In hindsight, the clinical reasoning that led to a provisional diagnosis of epilepsy in this case was not a necessarily sound clinical reasoning.

Subsequently, this patient developed mainly abdominal muscle spasms, which sometimes interfered with breathing. His case was reviewed, and the consensus was that collapse during manual evacuation of the bowel was related to autonomic dysreflexia and not due to epilepsy. As the patient requested, baclofen treatment was restarted initially at a dose of $5 \mathrm{mg}$ at night and then increased gradually to $10 \mathrm{mg}$ twice a day. This greatly alleviated his abdominal muscle spasms. He did not report any further seizures or episodes of collapse either in the lavatory or elsewhere.

However, in 2015, the patient again collapsed in the bathroom while performing manual evacuation of the bowel. He was found unresponsive in the bathroom by his daughter, who contacted the emergency services. On arrival at the Accident and Emergency Department of the local hospital, he seemed to exhibit expressive dysphasia and had developed a left-sided facial droop. In addition, initially he had a difficulty following commands. On admission, his Glasgow Coma Scale was $11 / 15$, blood pressure was $164 / 84 \mathrm{~mm} \mathrm{Hg}$, and temperature was $36.4^{\circ} \mathrm{C}$. ECG showed a ventricular rate of 56 per minute; PR interval $=194$ milliseconds; $Q R S$ duration $=113$ milliseconds; QT/QTc =457-440 milliseconds; and P-R-T axes $=74-35-42$. His chest was clear on auscultation. The patient was reassessed 40 minutes after presentation when his blood pressure had dropped to $97 / 59 \mathrm{~mm} \mathrm{Hg}$; he was much more alert and orientated, obeying commands and with a Glasgow Coma Scale of 15/15. His facial droop had resolved.

A noncontrast computed tomography scan of the head showed a grossly normal appearance of the cerebral parenchyma with normal gray/white matter differentiation, normal, symmetrical appearances of both middle cerebral arteries 
and unremarkable brainstem and cerebellum. There was no intracranial hemorrhage or surface collections, no space occupying lesions, or no mass effects. The ventricular system had a normal appearance, and the basal cisterns remained patent. The orbital contents were unremarkable as were the cranial vault and skull base. The overall conclusion was that there was no acute intracranial pathology.

Five days later, he developed painless swelling of the left knee and ankle. X-rays revealed a fracture of the tip of the left lateral malleolus and a supracondylar fracture of the left femur. A hinged knee brace was applied, which was locked in the most comfortable and appropriate position.

One morning in September 2016, his daughter found him collapsed and unresponsive in the bathroom at his home, sitting in his wheelchair next to the toilet with bloodied stool segments on the bathroom floor. He had a latex glove on his left hand and was holding a toilet tissue. Death was confirmed by a paramedic, and police officers attended the scene but found no suspicious circumstances. His district nurse had noted that the patient suffered a collapse three nights before his death after passing a very hard stool, but the nurse felt there was no need for his general practitioner to visit him. At the time of his death, his medication comprised baclofen, bisacodyl suppository, senna, and ranitidine.

A medicolegal postmortem examination was performed at the request of the coroner. This confirmed an old, relatively sharp curvature or angulation in the region of the lower cervical/upper thoracic vertebrae. The spinal cord appeared intact grossly but followed this angulation of the spinal column. There was no evidence of recent vertebral or spinal cord injury. The remainder of the examination was essentially unremarkable with no structural abnormality identified to account for death. In particular was no coronary artery stenosis, pneumonia, pulmonary embolism, or significant abnormality of the brain or of the urinary or gastrointestinal tracts. The rectum contained fairly hard feces. No histological, microbiological, or toxicological investigations were carried out. In the absence of any other obvious disease or cause for death found at autopsy and given the clinical history, the pathologist recorded the cause of death as autonomic dysreflexia secondary to spinal cord injury. The mechanism of death was postulated to be severe hypertension probably causing coronary artery spasm, acute myocardial ischemia, and fatal arrhythmia.

\section{Consent}

The authors confirm that written informed consent has been provided by the patient's daughter (the next of kin) to have the case details published.

\section{Discussion}

Silent autonomic dysreflexia may occur frequently in persons with complete spinal cord injury above the neurological level of T-6. In a study of ten such persons, the mean resting blood pressure was $104 / 65 \mathrm{mmHg} ; 60 \%$ of the subjects showed an increase in systolic blood pressure to $>150 \mathrm{mmHg}$, with the remaining $40 \%$ of the subjects reaching systolic blood pressures $>170 \mathrm{mmHg}$ at least once during their bowel program. ${ }^{7}$ Topical anesthetics are widely recommended to minimize the incidence and severity of autonomic dysreflexia, although no scientific evidence supports or refutes this practice. ${ }^{8} \mathrm{We}$ found application of $2 \%$ lidocaine jelly to the anal region prevented or reduced the severity of autonomic dysreflexia caused by manual bowel evacuation in patients with spinal cord injury.

Wan and Krassioukov reviewed 32 cases of death or life-threatening complications of autonomic dysreflexia published in PubMed; seven persons had died due to stroke, seizures, or myocardial ischemia occurring as a result of autonomic dysreflexia. ${ }^{9}$ Tan et al proposed that autonomic dysreflexia could predispose to coronary vasospasm via uncontrolled activity of the sympathetic nervous system. ${ }^{10}$ The disruption of sensory input from the myocardium to the brain in patients with spinal cord injury predisposed them to asymptomatic myocardial ischemia. These authors presented a case of intractable autonomic dysreflexia in a 36-year-old patient with chronic C-5 tetraplegia with silent myocardial ischemia secondary to coronary vasospasm in the absence of underlying cardiac pathology. MRI perfusion studies revealed normal left ventricular contractility and no evidence of coronary artery occlusion.

In our patient, autonomic dysreflexia during manual self-evacuation of the bowel resulted in collapse and finally death probably due to coronary artery spasm and consequent cardiac dysrhythmia. This patient first reported collapse occurred during manual bowel evacuation, which was initially attributed to side effects of baclofen treatment. Subsequently, we learnt that the patient experienced collapse only in the lavatory while performing manual bowel evacuation. All these episodes of collapse (ie, syncope) have been due to autonomic dysreflexia-associated bradycardia/asystole. The clearest evidence as to cause of the episodes was the fact that the patient died suddenly during one of them. This strongly supported autonomic dysreflexia-associated hypotension/ asystole, as opposed to baclofen-induced seizure, as the mechanism.

Buonaguro et al analyzed the relationship between epilepsy and intrathecal baclofen by studying a consecutive 
sample of 150 children with cerebral palsy or spasticity of cerebral origin, who received intrathecal baclofen, and concluded that, in children with spasticity of cerebral origin, intrathecal baclofen does not seem to aggravate or induce seizure activity. ${ }^{11}$ Rolland et al reported a 46-year-old patient who experienced two episodes of seizures after a short relapse of alcohol misuse while undergoing treatment with up to 240 $\mathrm{mg}$ /day of baclofen. ${ }^{12}$ Although both alcohol and baclofen may theoretically induce seizures and collapse, the authors largely ruled out the likelihood that either of these two drugs was solely responsible for their patient's seizures. They hypothesized that the seizures resulted from an interaction between alcohol and high dose baclofen and determined that this hypothesis is "probable" with Horn's Drug Interaction Probability Scale. In our patient, the highest dose of baclofen that was prescribed was only $10 \mathrm{mg}$ twice a day, and there was no history of alcohol misuse. Therefore, taking into consideration the time and location where the patient developed collapse, it is most unlikely that the collapses were a side effect of baclofen therapy.

There was an avoidable delay in recognizing that collapse during manual bowel self-evacuation was caused by autonomic dysreflexia. We also failed to foresee that this might be potentially fatal and therefore to suggest an alternative bowel management regime. The patient wished to live independently and preferred not to change his bowel management; nevertheless, if we had pointed out the possible consequences of his current regime, he may have proved more amenable to persuasion.

\section{Learning points}

1. Manual bowel evacuation in patients with spinal cord injury with neurological level T-6 and above may cause autonomic dysreflexia that can be asymptomatic and very rarely produce cardiac dysrhythmia, collapse, and even death.

2. In these patients, the use of $2 \%$ lidocaine jelly in anal region or per rectum prior to bowel evacuation may prevent or reduce the severity of autonomic dysreflexia caused by manual bowel evacuation. In a few patients, who continue to experience severe dysreflexia despite the use of topical anesthetic jelly, alternative bowel regimes such as the regular use of stimulant laxatives, transanal irrigation, colostomy, or ileostomy should be considered without delay.

\section{Acknowledgments}

The authors are grateful to The Chair Spinal Injuries Association, Liverpool, UK, Coloplast Ltd, Cambridgeshire, UK, and Mr Stephen Cronin, Liverpool, UK for funding the publication processing fee for this paper.

\section{Author contributions}

All authors contributed toward data analysis, drafting and revising the paper and agree to be accountable for all aspects of the work.

\section{Disclosure}

The authors report no conflicts of interest in this work.

\section{References}

1. Learning, candour and accountability: a review of the way NHS trusts review and investigate the deaths of patients in England. Care Quality Commission; 2016. Available from: http://www.cqc.org.uk/sites/ default/files/20161213-learning-candour-accountability-full-report. pdf. December 13, 2016.

2. Hector SM, Biering-Sørensen T, Krassioukov A, Biering-Sørensen F. Cardiac arrhythmias associated with spinal cord injury. J Spinal Cord Med. 2013;36(6):591-599.

3. Sadaka F, Veremakis C. Bradycardia Secondary to Cervical Spinal Cord Injury. St John's Mercy Medical Center, St Louis University, MO, USA. 395-402. Available from: https://www.intechopen.com/download/ pdf/30097. Accessed August 4, 2017.

4. Lehmann KG, Lane JG, Piepmeier JM, Batsford WP. Cardiovascular abnormalities accompanying acute spinal cord injury in humans: incidence, time course and severity. J Am Coll Cardiol. 1987;10(1):46-52.

5. Wirth B, van Hedel HJ, Kometer B, Dietz V, Curt A. Changes in activity after a complete spinal cord injury as measured by the Spinal Cord Independence Measure II (SCIM II). Neurorehabil Neural Repair. 2008;22(2):154-153.

6. Trønnes H, Berg A. Hjertestans i en 10 måneder gammel gutt med spinal Ledningsskader. [Cardiac arrest in a 10-month-old boy with spinal cord injury]. Tidsskr Nor Laegeforen. 2012;132(9):1099-1102. Norwegian.

7. Kirshblum SC, House JG, O'Connor KC. Silent autonomic dysreflexia during a routine bowel program in persons with traumatic spinal cord injury: a preliminary study. Arch Phys Med Rehabil. 2002;83(12): 1774-1776.

8. Cosman BC, Vu TT, Plowman BK. Topical lidocaine does not limit autonomic dysreflexia during anorectal procedures in spinal cord injury: a prospective, double-blind study. Int J Colorectal Dis. 2002;17(2):104-108.

9. Wan D, Krassioukov AV. Life-threatening outcomes associated with autonomic dysreflexia: a clinical review. J Spinal Cord Med. 2014;37(1):2-10.

10. Tan SW, Rahman ZB, Fauzi AA, Latif LA, Hasnan N. Coronary vasospasm in intractable autonomic dysreflexia. Spinal Cord Ser Cases. 2016;2:16030.

11. Buonaguro V, Scelsa B, Curci D, Monforte S, Iuorno T, Motta F. Epilepsy and intrathecal baclofen therapy in children with cerebral palsy. Pediatr Neurol. 2005;33(2):110-113.

12. Rolland B, Deheul S, Danel T, Bordet R, Cottencin O. A case of de novo seizures following a probable interaction of high-dose baclofen with alcohol. Alcohol Alcohol. 2012;47(5):577-580. 
International Medical Case Reports Journal

The International Medical Case Reports Journal is an international, peer-reviewed open-access journal publishing original case reports from all medical specialties. Previously unpublished medical posters are also accepted relating to any area of clinical or preclinical science. Submissions should not normally exceed 2,000 words or
4 published pages including figures, diagrams and references. The manuscript management system is completely online and includes a very quick and fair peer-review system, which is all easy to use. Visit $\mathrm{http}: / /$ www.dovepress.com/testimonials.php to read real quotes from published authors.

Submit your manuscript here: https://www.dovepress.com/international-medical-case-reports-journal-journal 